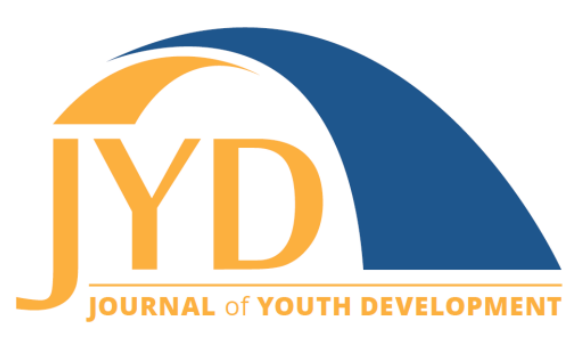

http://jyd. pitt. edu/ | Vol. 13 Issue 4 DOI 10.5195/jyd.2018.586 | ISSN 2325-4017 (online)

\title{
Diversity and Inclusion as Essential Elements of 4-H Youth Development Programs
}

\author{
Rachel Sumner \\ Bronfenbrenner Center for Translational Research, Cornell University \\ ras525@cornell.edu \\ Andy Turner \\ Bronfenbrenner Center for Translational Research, Cornell University \\ ast4@cornell.edu
}

Anthony L. Burrow

Department of Human Development, Cornell University

alb325@cornell.edu

\begin{abstract}
Diversity and inclusion are essential elements of 4-H's goals related to positive youth development, workforce development, and organizational sustainability. Previous research has examined Cooperative Extension professionals' attitudes on this topic, demonstrating that most of them recognize the importance of diversity and inclusion in 4-H. Here we present results from a survey of adolescents participating in New York state 4-H programs assessing their endorsement of racial/ethnic diversity and inclusion in 4-H. Results revealed that, overall, youth felt positively toward this kind of diversity and inclusion in 4-H, and endorsement was most strongly predicted by a learning orientation that emphasizes acquiring new information through intergroup contact. We conclude with considerations for 4-H programs seeking to help young people develop and maintain an openness to diversity and inclusion.
\end{abstract}

Key words: 4-H, diversity, inclusion, positive youth development, learning orientation

4-H has set ambitious goals to deliver positive youth development programs to 10 million youth nationally by the year 2025, up from the current reach of approximately 6 million youth per year (e.g., National 4-H Council, 2016). To accomplish this goal, it has identified the need to

\footnotetext{
(cc) EY New articles in this journal are licensed under a Creative Commons Attribution 4.0 License. This journal is published by the University Library System, University of Pittsburgh and is cosponsored by the University of Pittsburgh Press. The Journal of Youth Development is the official peer-reviewed publication of the National Association of Extension 4-H Agents and the National AfterSchool Association.
} 


\section{Diversity and Inclusion: Essential Elements of 4-H}

reach more urban youth and more ethnically diverse youth as a core component of its growth strategy. As outlined in their recent strategic plan, 4-H's ambitious vision for growth is aimed at achieving a participation portfolio that "reflects the population demographics, vulnerable populations, diverse needs and social conditions of the country" (National 4-H Council, 2017, p. 2). Increased racial and ethnic diversity and inclusion are critical components of achieving not only growth, but also 4-H's other aims around positive youth development outcomes, supporting workforce development in the $21^{\text {st }}$ century, and overall sustainability for its programs.

Including more youth from different racial and ethnic backgrounds would likely alter the program experience for young people who are already part of $4-\mathrm{H}$, most of whom are White. For example, 10 counties throughout New York state (where the present research was conducted) had 4-H community club youth enrollments that were either 99 or $100 \%$ white, although the populations in those counties ranged from $70 \%$ to $96 \%$ white (data for $54 \mathrm{New}$ York counties from 2015-2016, accessed at 4Hdata.com). The youth in these clubs currently experience $4-\mathrm{H}$ as a racially homogeneous context-for some, even more so than the counties in which they live-underscoring the importance of investigating how young people feel about diversity and inclusion in 4- $\mathrm{H}$. Previous research has demonstrated that many Extension professionals understand the importance of focusing on diversity and inclusion in 4-H programs (e.g., Ingram, 1999; LaVergne, 2013), and here we will present results from a survey asking adolescent 4-H participants about their attitudes towards racial and ethnic diversity and inclusion in 4-H. In addition to building on existing work by examining 4-H youth participants' endorsement of policies and goals related to diversity and inclusion, we also explored individual characteristics that predict greater endorsement of diversity and inclusion in 4-H. We conclude with considerations for 4-H programs seeking to help young people develop and/or maintain an openness to diversity and inclusion.

\section{Diversity and Inclusion in 4-H's Positive Youth Development Learning Model}

The positive youth development perspective emphasizes every young person's potential to cultivate the strengths and skills that will help them thrive (Lerner, Almerigi, Theokas, \& Lerner, 2005). Strengths and skills that involve interacting with others, especially people from different backgrounds, are increasingly important for success, and surveys with Extension professionals in Pennsylvania and West Virginia have found that the majority of those adults consider diversity and inclusion to be important elements of 4-H programming (Ingram, 1999; LaVergne, 2013). There is also evidence that adults' own attitudes about diversity and inclusion affect the 
Diversity and Inclusion: Essential Elements of 4-H

intentions of the youth they work with (e.g., intending to include or exclude a child with special education needs) (Grütter \& Meyer, 2014), but it remains unknown whether Extension professionals' positive attitudes towards diversity and inclusion in the program are shared by 4$\mathrm{H}$ youth.

Diversity and inclusion are also essential to $4-\mathrm{H}$ programs' workforce development efforts. Business leaders have described communication skills and an ability to interact with others, especially across different group memberships, as highly desirable attributes in a job applicant (Engberg, 2007; Hilton, 2008). Even "low-skill" jobs that require little formal education are increasingly demanding strong interpersonal skills (Hilton, 2008). Youth who can speak to their experiences as part of a racially and ethnically diverse 4-H program may appeal to employers looking to hire individuals who value diversity and inclusion and can demonstrate experience working effectively across difference. Creating a more diverse community of 4-H participants will enhance the program's ability to facilitate the development of these skills and attitudes among participating youth. Achieving these goals will be much easier and more successful if young people already engaged in 4-H are excited about diversity and inclusion in their programs, so it is important to understand what individual motivations or characteristics might be linked to endorsing diversity and inclusion.

While national projections suggest that by 2044, ethnic minority individuals will comprise a majority of the total U.S. population (Colby \& Ortman, 2015), this minority-majority benchmark has already been surpassed among babies born in the United States (Cohn, 2016). Likewise, ethnic minorities are roughly half (48\%) of those who are younger than 18 years old, accounting for a much larger proportion than their adult counterparts (ethnic minorities represent $37 \%$ of the current adult population) (Colby \& Ortman, 2015). Thus, ethnic diversity represents a defining characteristic of younger generations. It is also true, however, that many young people do not seize opportunities for intergroup interaction when they are available (e.g., choosing to sit with same race peers in the cafeteria; e.g., Al Ramiah, Schmid, Hewstone, \& Floe, 2015), and out-of-school contexts can provide important opportunities for developing relationships with peers from different backgrounds (Knifsend \& Juvonen, 2017). In addition to promoting the development of critical social skills, being friends with a member of an outgroup is also related to reduced prejudice and more positive intergroup attitudes over time (Binder et al., 2009; Davies, Tropp, Aron, Pettigrew, \& Wright, 2011). Given this existing work, participants' previous intergroup contact will be included in our analysis as a potential predictor of their endorsement of diversity and inclusion in 4-H. 
Diversity and Inclusion: Essential Elements of 4-H

There is also existing empirical evidence that one's underlying motivation to engage in intergroup contact is related to comfort with and interest in such interactions (Migacheva \& Tropp, 2012). Two goal orientations were included in Migacheva and Tropp's (2012) studies: learning orientation, or wanting to acquire new information and knowledge through intergroup contact; and performance orientation, or wanting to use intergroup contact to verify one's own abilities and attributes. Adolescents who scored higher on their measure of learning orientation were more comfortable with and more interested in intergroup contact. In the present study, we investigated whether either of these goal orientations was linked to adolescents' endorsement of diversity and inclusion within $4-\mathrm{H}$, which is more reflective of attitudes towards diversity and inclusion policies than it is of their own personal enthusiasm for intergroup contact. Exposure to diversity and inclusion policies can lead to White adults feeling concerned about their own potential exclusion from organizations implementing these policies (Dover, Major, \& Kaiser, 2016). As such, it is important to understand how adolescents who are currently part of 4-H, most of whom are White, may react to the organization's concerted effort to recruit and retain more youth from other racial and ethnic backgrounds. The outcome of interest in the current study, endorsement of diversity and inclusion in 4-H, captures participants' attitudes not about diversity and inclusion in general, but specifically as they relate to the goals and implementation of $4-\mathrm{H}$ programming.

\section{Method}

\section{Participants and Procedure}

Adolescents (ages 14-18) currently enrolled in at least one New York state 4-H program were recruited for participation in a study about their experiences in 4-H. This study involved completing three online surveys, each administered approximately one month apart. Data reported here were collected in the first survey, for which participants were compensated with a $\$ 10$ gift card. In addition to the scales described below, participants were presented with survey questions related to their demographic information, purpose in life, positive affect, estimates of different racial and ethnic groups' representation in the U.S. population, and their willingness to engage in different behaviors related to diversity and racial inequality (e.g., post a message on social media, participate in a protest). The variables included in our analyses, described below, were chosen because of their relevance to youths' potential experience in more racially and ethnically diverse 4-H programs (e.g., endorsement of diversity within 4-H, motivation when interacting with people from a different racial or ethnic background). 
Diversity and Inclusion: Essential Elements of 4-H

Eighty-seven adolescents completed the survey from which these data were derived ( $M_{\text {age }}=$ $15.65, S D=1.16)$. In this sample Whites were slightly overrepresented $(87 \%)$ compared to their representation among youth enrolled in New York 4-H programs (80\%; Interactive New York 4-H ES-237 report, 2016). Seventy-five percent of the sample identified as female, $22 \%$ as male, $2 \%$ as genderqueer/gender non-conforming, and one participant preferred to not indicate their gender.

\section{Measures}

\section{Endorsement of Diversity and Inclusion in 4-H}

Our outcome of interest, endorsement of diversity and inclusion in 4-H, was assessed with six statements such as "4-H should be an environment where differences are valued," and "One of the goals of 4-H should be to teach people from different racial, ethnic, and cultural backgrounds how to live and work together." Participants indicated their level of agreement with each statement using a scale from 1 (Strongly Disagree) to 5 (Strongly Agree) and the scale demonstrated adequate reliability $(a=.91)$. The items used in this measure were adapted from an existing scale (Plaut, Garnett, Buffardi, \& Sanchez-Burks, 2011).

\section{Previous Interracial Contact}

The survey contained seven items asking participants about the quantity and quality of their previous contact with people from different racial groups (e.g., "My experiences with people of other racial groups have generally been pleasant" and "I have rarely interacted with people of different racial groups" (reverse-scored)), and they rated their agreement with each of these statements on a scale from 1 (Strongly Disagree) to 7 (Strongly Agree). Reliability for this measure was adequate $(a=.78)$.

\section{Learning and Performance Orientations}

Using scales developed by Migacheva and Tropp (2012), we assessed two possible motivations for intergroup interaction. Participants rated their level of engagement in six statements related to learning orientation (e.g., "When you're interacting with people from a different racial/ethnic background than yours, how much are you interested in their ideas and what they have to say?") and six items related to performance orientation (e.g., "When you're interacting with people from a different racial/ethnic background than yours, how much do you wonder what they will think about you?"). Ratings were provided on a scale from 1 (Not at all) to 5 (Very 
much) and reliabilities were adequate (learning orientation $a=.87$, performance orientation $a$ $=.85)$.

\section{Exposure to Racial Diversity Within 4-H}

Because the racial composition of 4-H programs varies from county to county, we also used 4Hdata.com to find the aggregate racial composition of youth enrolled in 4-H programs in each participant's county (most recent data available were from the 2015-2016 program year). In each county from which our participants were drawn, White youth comprised the majority of youth enrolled in 4-H programs. In our analyses, we controlled for participants' exposure to racial diversity within $4-\mathrm{H}$ by including in our analysis the percentage of Whites among youth enrolled in their county's 4-H programs.

\section{Results}

Bivariate correlations, in addition to means and standard deviations, for all study variables are presented in Table 1.

Table 1. Bivariate Correlations, Means, and Standard Deviations of Study Variables

\begin{tabular}{|c|c|c|c|c|c|c|}
\hline & 1 & 2 & 3 & 4 & 5 & 6 \\
\hline \multicolumn{7}{|l|}{ 1. Participant race ( $0=$ White, $1=$ Not White $)$} \\
\hline 2. Whites' representation in county $4-\mathrm{H}$ programs & $-0.53 * *$ & & & & & \\
\hline 3. Previous interracial contact & $0.26 *$ & $-0.39 * *$ & & & & \\
\hline 4. Learning orientation & 0.1 & -0.07 & $0.51^{* *}$ & & & \\
\hline 5. Performance orientation & 0.06 & 0.04 & -0.15 & 0.08 & & \\
\hline 6. Endorsement of diversity and inclusion in $4-\mathrm{H}$ & 0.05 & -0.08 & $0.27 *$ & $0.52 * *$ & 0.17 & \\
\hline Mean & & 92.87 & 3.53 & 3.28 & 2.67 & 4.19 \\
\hline Standard deviation & & 5.3 & 0.67 & 0.81 & 0.93 & 0.82 \\
\hline
\end{tabular}

Note. ${ }^{*} p<.05, * * p<.01$ 
Diversity and Inclusion: Essential Elements of 4-H

Overall, participants in this study strongly endorsed diversity and inclusion in 4-H. The mean score was $4.20(S D=.82)$ on a scale with a maximum score of 5 . In order to investigate which characteristics predicted adolescents' endorsement of diversity and inclusion in 4- $\mathrm{H}$, we conducted a hierarchical linear regression. A binary variable indicating participant race (White/Not White) and previous interracial contact were included as predictors in the first step of this regression, along with the percent of White youth comprising their home county's 4-H enrollment. Including these variables in the first step of the regression enables us to examine whether youths' own race or their contact with people from other backgrounds predict the extent to which they endorse diversity and inclusion in 4-H. In the second step of this regression, we included participants' learning and performance orientation scores, investigating what, if any, role youths' motivation plays in predicting their endorsement of diversity and inclusion in 4-H above and beyond their own race and previous interracial contact experiences. All predictors (other than binary race variable) were standardized.

Previous interracial contact significantly predicted endorsement of diversity and inclusion in step one, but when learning and performance orientations were added in step two previous contact was no longer significant. The only variable that significantly predicted endorsement of diversity and inclusion in 4-H in the full regression was learning orientation; wanting to learn through intergroup contact predicted greater endorsement of diversity and inclusion in $4-\mathrm{H}$. Results are presented in Table 2.

Table 2. Hierarchical Linear Regression Predicting Endorsement of Diversity and Inclusion in 4-H.

\begin{tabular}{|c|c|c|c|c|c|c|}
\hline & \multicolumn{3}{|c|}{ Step 1} & \multicolumn{3}{|c|}{ Step 2} \\
\hline & $\boldsymbol{B}$ & SE & $\boldsymbol{\beta}$ & $\boldsymbol{B}$ & SE & $\boldsymbol{\beta}$ \\
\hline Participant Race ( $0=$ White, $1=$ Not White $)$ & -0.1 & 0.3 & -0.04 & -0.2 & 0.27 & -0.08 \\
\hline Whites' representation in county $4-\mathrm{H}$ programs & 0.02 & 0.11 & 0.02 & -0.05 & 0.1 & -0.06 \\
\hline Previous interracial contact & 0.28 & 0.1 & $.34 * *$ & 0.09 & 0.1 & 0.1 \\
\hline Learning orientation & & & & 0.38 & 0.09 & $.47 * *$ \\
\hline Performance orientation & & & & 0.14 & 0.08 & 0.17 \\
\hline
\end{tabular}

Note. $* p<.05, * * p<.01$ 


\section{Discussion}

The results of our survey suggest that youth may be very receptive to increased diversity and inclusion in 4-H. We found that most of our participants agreed with statements like "4-H should be an environment where differences are valued," and "One of the goals of 4-H should be to teach people from different racial, ethnic, and cultural backgrounds how to live and work together." In our analyses examining potential predictors of participants' endorsement of diversity and inclusion in 4- $\mathrm{H}$, learning orientation-wanting to use interactions with someone from a different background as an opportunity to learn things-emerged as a significant predictor. Having a higher score on the measure of learning orientation predicted greater endorsement of diversity and inclusion within $4-\mathrm{H}$, even when controlling for some demographic and individual difference characteristics. By investigating how adolescent 4-H'ers feel about diversity and inclusion in their programs and examining potential predictors of their endorsement of diversity and inclusion, the current study further elucidated how the 4- $\mathrm{H}$ community feels about these increasingly relevant issues.

In our study, learning orientation emerged as the most robust predictor of endorsing diversity and inclusion in 4-H. Previous research had linked adolescents' learning orientation to their interest in and comfort with intergroup contact (Migacheva \& Tropp, 2012), and this study demonstrated a link between this same motivation and a different aspect of intergroup relations: endorsement of programmatic goals associated with diversity and inclusion. Helping youth cultivate genuine curiosity and empathy towards people from different backgrounds may contribute to their learning orientation, and $4-\mathrm{H}$ is poised to be particularly supportive in this regard because of its many opportunities for cooperative learning and collaboration (e.g., teamoriented, youth-directed projects in animal science, STEM, or community service). Indeed, the positive effects of intergroup contact are amplified in situations that require youth from different backgrounds to cooperate on shared goals (Beelmann \& Heinemann, 2014), and a review of existing programs aimed at improving intergroup attitudes found the biggest impact among those in which youth actually interacted with people from different backgrounds, and received training around empathy and/or perspective taking (Beelmann \& Heinemann, 2014). For youth in 4-H, being able to call upon their common identity as a "4-H'er" can focus attention on what they have in common (Gómez, Dovidio, Gaertner, Fernández, \& Vázquez, 2013), perhaps easing some reluctance to engage with youth from different backgrounds. Emphasizing shared identity is not meant to obscure differences between people-indeed, it should be acknowledged that everyone belongs to multiple groups (e.g., racial and ethnic groups, gender, family), but that everyone also shares membership in at least one social group as part of $4-\mathrm{H}$. 
Diversity and inclusion are relevant to all youth programs, even those serving a population that is racially and/or ethnically homogeneous, because interacting with people from different backgrounds is a key to success in the modern world. In considering the potential implications of our findings, we recognize that diversity means difference or variety. Most groups of people are diverse in some ways and everyone has unique characteristics that can contribute to social differences within the group (Blaine \& Brenchley, 2018). In addition to race and ethnicity, characteristics such as gender, gender identity, socioeconomic status (SES), sexual orientation, religion, primary language, country of origin, disability, and geographic context (e.g., urban, suburban, rural) also feature in creating diverse groups. We hope that readers who live and work in communities that are relatively racially/ethnically homogeneous will think about all of the ways that they are actually surrounded by and participating in diversity, and to consider how they can use these findings to facilitate engagement with diversity and inclusion in their 4-H programs.

Youth who want to see different identities, cultures, and viewpoints represented in their 4-H programs may rely on local demographics as a relevant point of comparison (e.g., Are the groups I encounter through 4-H more or less racially diverse than groups I encounter at school? At the grocery store?). When being intentional about cultivating a youth development program that embodies diversity and inclusion, the diversity of the local area is likely a good benchmark with which to compare the diversity of the program participants and staff: How do the characteristics of the staff and youth in your program compare to the overall population of your geographic area? Who joins the program, and who chooses to stay in the program? Information about county demographics and local $4-\mathrm{H}$ enrollment demographics is available for some states at 4 Hdata.com.

Increasing diversity has implications beyond changing the composition of a program's youth enrollments. Successful and sustainable youth development programs may also need to examine substantial questions regarding the appeal of their activities, curricula, and staff to all youth. For example, the topics chosen for youth to explore, the settings where learning takes place, and the cultural competencies of the educators guiding youth learning all conspire to create an experience for youth that is either supportive and inclusive of more youth from different backgrounds, or unsupportive and therefore more likely to lead to stagnation or declines in enrollment (e.g., Gutiérrez, Larson, Raffaelli, Fernandez, \& Guzman 2017). Programs seriously invested in supporting youth development, diversity, and inclusion may need to consider structural and content-related adaptations that are meaningful to the new communities 
Diversity and Inclusion: Essential Elements of 4-H

served. Although some current 4-H youth may be enthusiastic about these adaptations and their inherent learning opportunities, others might be wary of changes if they are perceived as fundamentally altering the 4-H programs they value.

Some adults have concerns about whether focusing on diversity and inclusion might alienate existing program participants (Ingram, 1999) and they may feel as though they lack tools and ideas necessary to engage in effective culturally responsive work with youth (Walter \& Grant, 2011). For those who are unsure about how current youth participants would react to more diversity and inclusion in the program, it may be helpful to facilitate candid conversations with youth about which aspects of diversity and inclusion they are excited about or wary of; perhaps some young people are energized by the idea of being able to connect to peers and adults from a different racial or ethnic background, while others are more enthusiastic about increased program content related to other cultures and experiences. These responses can be used to inform program-specific diversity and inclusion strategies, in addition to providing fodder for important conversations about difference as programs move towards more diverse and inclusive population and content. A potential limitation of conversations such as this, and of the study presented here, is that young people will feel compelled to respond in a way that is socially desirable. Expecting that they may face adverse repercussions for expressing unpopular sentiments (e.g., lack of enthusiasm for diversity and inclusion), some young people who completed this survey may have provided responses that were not completely honest.

There are other limitations of the current study that must be noted. One potential limitation of this study is that all data were derived from a small self-selecting sample drawn from one type of youth development program; results may differ if participants were recruited from programs other than 4-H. Our focus on 4-H participants, however, enables us to more directly build on previous research exploring the diversity attitudes of adults involved with 4-H (e.g., Ingram, 1999; LaVergne, 2013). An additional limitation is that we did not collect any data about how much change our participants perceived in their own 4-H programs. The extent to which they endorse diversity and inclusion in 4-H may shift if youth do not enjoy or value programmatic or curricular changes driven by diversity and inclusion efforts, but our findings suggest that those with a learning orientation may be best poised to adapt to changes in program content. Finally, we tried to control for demographics of local 4-H programming by including in our regressions the percentage of White enrollees within each county. This is a blunt approximation of participants' exposure to racial and ethnic diversity during their participation in 4- $\mathrm{H}$, as that statistic does not capture information at the program-specific level, nor does it encapsulate 
Diversity and Inclusion: Essential Elements of 4-H

experiences that may take place outside of the club context (e.g., 4-H camps, after-school programming, or statewide events like fairs).

\section{Conclusion}

Although it was established over 100 years ago and emerged from the largely agrarian and rural programming focus of Cooperative Extension, 4-H has shown itself to be capable of adapting and empowering youth with skills that are relevant for their time and place. For example, engaging youth in the agriculture and food system by working with animals and crops has been a major focus for decades that is still relevant today. However, in addition to learning the best methods for raising crops and livestock, youth in 4- $\mathrm{H}$ are now also learning how drone technology can be used to monitor crop health and guard against invasive species.

Technological advances and demographic trends suggest that the coming years will continue to present new challenges and opportunities for young people and the organizations that work with them. Shifting demographics in particular have spurred youth-serving organizations, including $4-\mathrm{H}$, to increase focus on issues of diversity and inclusion.

Throughout this paper we have described a number of important reasons that 4-H should continue to focus on attracting and serving more youth from different backgrounds. Specifically, diversity and inclusion are critical components of achieving positive youth development outcomes, supporting workforce development in the $21^{\text {st }}$ century, necessary for the overall sustainability for youth-serving organizations, and, as suggested by our survey results, welcomed by current 4-H program participants, especially those oriented towards learning. With a continued focus on diversity and inclusion, 4-H will be better-positioned to help more youth form deep and meaningful connections with youth and adults from diverse backgrounds, playing an essential role in providing the diverse, inclusive and supportive environments young people need to develop into competent, caring, contributing members of society.

\section{References}

Al Ramiah, A. A., Schmid, K., Hewstone, M., \& Floe, C. (2015). Why are all the White (Asian) kids sitting together in the cafeteria? Resegregation and the role of intergroup attributions and norms. British Journal of Social Psychology, 54, 100-124. doi:10.1111/bjso.12064

Beelmann, A., \& Heinemann, K. S. (2014). Preventing prejudice and improving intergroup attitudes: A meta-analysis of child and adolescent training programs. Journal of Applied Developmental 
Diversity and Inclusion: Essential Elements of 4-H

Psychology, 35, 10-24. Retrieved from

http://www.sciencedirect.com/science/article/pii/S0193397313001007

Binder, J., Zagefka, H., Brown, R., Funke, F., Kessler, T., Mummendey, A., ... \& Leyens, J. P. (2009).

Does contact reduce prejudice or does prejudice reduce contact? A longitudinal test of the contact hypothesis among majority and minority groups in three European countries. Journal of Personality and Social Psychology, 96, 843-856. doi:10.1037/a0013470

Blaine, B. E., \& Brenchley, K. J. M. (2018). Understanding the psychology of diversity ( $3^{\text {rd }}$ ed.). Thousand Oaks, CA: Sage Publications.

Cohn, D. (2016, June 23). It's official: Minority babies are the majority among the nation's infants, but only just. Pew Research Center Fact Tank. Retrieved from http://www.pewresearch.org/facttank/2016/06/23/its-official-minority-babies-are-the-majority-among-the-nations-infants-but-onlyjust/

Colby, S. L., \& Ortman, J. M. (2015). Projections of the size and composition of the U.S. population: 2014 to 2060. Retrieved from https://www.census.gov/content/dam/Census/library/publications/2015/demo/p25-1143.pdf

Davies, K., Tropp, L. R., Aron, A., Pettigrew, T. F., \& Wright, S. C. (2011). Cross-group friendships and intergroup attitudes: A meta-analytic review. Personality and Social Psychology Review, 15, 332351. doi:10.1177/1088868311411103

Dover, T. L., Major, B., \& Kaiser, C. R. (2016). Members of high-status groups are threatened by prodiversity organizational messages. Journal of Experimental Social Psychology, 62, 58-67. doi:10.1016/j.jesp.2015.10.006

Engberg, M. E. (2007). Educating the workforce for the $21^{\text {st }}$ century: A cross-disciplinary analysis of the impact of the undergraduate experience on students' development of a pluralistic orientation. Research in Higher Education, 48(3), 283-317. Retrieved from https://link.springer.com/article/10.1007/s11162-006-9027-2

Gómez, Á., Dovidio, J. F., Gaertner, S. L., Fernández, S., \& Vázquez, A. (2013). Responses to endorsement of commonality by ingroup and outgroup members: The roles of group representation and threat. Personality and Social Psychology Bulletin, 39(4), 419-431. Retrieved from http://journals.sagepub.com/doi/abs/10.1177/0146167213475366

Grütter, J., \& Meyer, B. (2014). Intergroup friendship and children's intentions for social exclusion in integrative classrooms: the moderating role of teachers' diversity beliefs. Journal of Applied Social Psychology, 44, 481-494. doi:10.1111/jasp.12240/abstract

Gutiérrez, V., Larson, R. W., Raffaelli, M., Fernandez, M., \& Guzman, S. (2017). How staff of youth programs respond to culture-related incidents: Nonengagement versus going "full right in." Journal of Adolescent Research, 32, 64-93. doi:10.1177/0743558416664028 
Diversity and Inclusion: Essential Elements of 4-H

Hilton, M. (2008). Skills for work in the $21^{\text {st }}$ century: What does the research tell us?. The Academy of Management Perspectives, 22, 63-78. doi:10.5465/amp.2008.35590354

Ingram, P. D. (1999). Attitudes of extension professionals toward diversity education in 4-H programs. Journal of Extension, 37, Article 1FEA3. Retrieved from https://www.joe.org/joe/1999february/a3.php

Interactive New York 4-H ES-237 report. (2016). Proportion of youth reached. Retrieved from http://4hdata.com/ny-es-237

Knifsend, C. A., \& Juvonen, J. (2017). Extracurricular activities in multiethnic middle schools: Ideal Context for Positive Intergroup Attitudes?. Journal of Research on Adolescence, 27, 407-422. doi:10.1111/jora.12278

LaVergne, D. D. (2013). Diversity inclusion in 4-H youth programs: Examining the perceptions among West Virginia 4-H youth professionals. Journal of Extension, 51, Article 4FEA1. Retrieved from https://www.joe.org/joe/2013august/a1.php

Lerner, R. M., Almerigi, J. B., Theokas, C., \& Lerner, J. V. (2005). Positive youth development: A view of the issues. The Journal of Early Adolescence, 25, 10-16. Retrieved from http://journals.sagepub.com/doi/pdf/10.1177/0272431604273211

Migacheva, K., \& Tropp, L. R. (2012). Learning orientation as a predictor of positive intergroup contact. Group Processes \& Intergroup Relations, 16, 426-444. doi:10.1177/1368430212455854

National 4-H Council. (2016). Survey shows American youth feel today's leaders have a different agenda: They lack skills to lead themselves [Press release]. Retrieved from https://4-h.org/media/surveyshows-american-youth-feel-todays-leaders-have-a-different-agenda-they-lack-skills-to-leadthemselves/

National 4-H Council. (2017). 4-H Youth Development: A 2025 vision. Retrieved from https://nifa.usda.gov/sites/default/files/resources/National\%204H\%20Strategic\%20Plan\%202017.pdf

Plaut, V. C., Garnett, F. G., Buffardi, L. E., \& Sanchez-Burks, J. (2011). "What about me?" Perceptions of exclusion and Whites' reactions to multiculturalism. Journal of Personality and Social Psychology, 101(2), 337-353. doi:10.1037/a0022832

Walter, A., \& Grant, S. (2011). Developing culturally responsive youth workers. Journal of Extension, 49, Article 5FEA9. Retrieved from https://www.joe.org/joe/2011october/a9.php 